\title{
Composites Based on Polypropylene and Talc: Processing Procedure and Prediction Behavior by Using Mathematical Models
}

\author{
Laiza Marinho Racca, ${ }^{1}$ Elen Beatriz Acordi Vasques Pacheco, ${ }^{1,2}$ \\ Luiz Carlos Bertolino, ${ }^{3}$ Cristiane Xavier da Silva Campos, ${ }^{4}$ Monica Calixto de Andrade, ${ }^{5}$ \\ Ana Maria Furtado de Sousa $\mathbb{D}^{6},{ }^{6}$ and Ana Lúcia Nazareth da Silva $\mathbb{D}^{1,2}$ \\ ${ }^{1}$ Instituto de Macromoléculas Professora Eloisa Mano, Universidade Federal do Rio de Janeiro, Rio de Janeiro, \\ ZIP/Post 21941-598, RJ, Brazil \\ ${ }^{2}$ Programa de Engenharia Ambiental, Universidade Federal do Rio de Janeiro, Rio de Janeiro, ZIP/Post 21941-909, RJ, Brazil \\ ${ }^{3}$ Centro de Tecnologia Mineral (CETEM), Rio de Janeiro, RJ, Brazil \\ ${ }^{4}$ CENPES/PETROBRAS, Rio de Janeiro, RJ, Brazil \\ ${ }^{5}$ Instituto Politécnico do Rio de Janeiro, Universidade do Estado do Rio de Janeiro, Nova Friburgo, ZIP/Post 28.625-570, Brazil \\ ${ }^{6}$ Instituto de Química, Universidade do Estado do Rio de Janeiro, Rio de Janeiro, ZIP/Post 20550-900, RJ, Brazil
}

Correspondence should be addressed to Ana Lúcia Nazareth da Silva; ananazareth@ima.ufrj.br

Received 6 March 2018; Accepted 20 September 2018; Published 1 November 2018

Academic Editor: Gary Wysin

Copyright (C) 2018 Laiza Marinho Racca et al. This is an open access article distributed under the Creative Commons Attribution License, which permits unrestricted use, distribution, and reproduction in any medium, provided the original work is properly cited.

\begin{abstract}
iPP/Talc composites were produced, with different methods of filler addition in iPP matrix. Two different grades of Talc were used for comparison. The tensile tests results showed that talc particles promoted an improvement in composite rigidity, indicating the reinforcing effect of the talc particles in the iPP matrix. However, PP/talc-based composites that were prepared from a masterbatch and with talc grade with smaller particle size showed a better efficiency on dispersion/distribution of particle filler on the thermoplastic matrix, resulting in an improvement in Young's modulus property, even with higher filler contents. SEM analyses evaluated the composite morphologies and different mathematical models were used as a tool on prediction of mechanical behaviour of the materials. It was observed that the results of Young's modulus of the composites can be adjusted by different models, depending on the talc characteristics and the mixing procedure used.
\end{abstract}

\section{Introduction}

The production of composites has been widely studied, once there is a large filler variety available, as well its features. Because of this, inorganic fillers are often compounded into thermoplastic polymer for reducing the cost of plastic products and improve some properties, such as rigidity, impact strength, hardness, wear resistance, and toughness. These final properties may vary, depending on dispersion degree of filler on polymer matrix, beyond the interaction level between composite phases. It is also important to consider composite design protocol that fillers are available in several shapes and sizes, which leads different properties in the final composite [1-12].
According to literature, the factors which affect inorganic filler's performance on the composition are as follows [7, 8]: (a) Filler content: fillers tend to have a significant influence on properties of composites in a certain content range. Above a critical concentration value, the filler amount is such that there will be interactions between particles (cluster formation), generating stress concentration points, which will affect the mechanical properties. (b) Size and particle size distribution, in general, are used the ones with 1-10 microns. Fillers with high particle size usually are tension accumulators, which act as a fracture propagation points, and besides promote an increase in viscosity (and a consequently difficult processing), while very small particles are difficult to disperse and may agglomerate, forming large particles due 
the high interfacial tension. (c) Distribution and dispersion filler in polymeric matrix: it is important to ensure that the same filler content is in the whole volume of the composite; thus, mechanical response may be uniform, independent of area chosen for testing. Dispersion can be controlled by processing parameters (as screw profile used in extrusion, for example). (d) Shape and aspect ratio of fillers: fillers can be related by its aspect ratio (diameter/length). Materials with high aspect ratio are anisotropic materials and when they oriented in flow direction show a high reinforcing effect. The greater the aspect ratio of the particle, the greater the reinforcing effect.

Talc is a very conventional filler to reinforce iPP due to its low cost and high aspect ratio [13]. The final properties of composites based on iPP/talc are dependent on the inherent characteristics, their orientation, and the crystallinity morphology of the matrix. Talc filler enables improvement of both thermal and mechanical properties [14, 15].

\section{Mathematical Models}

The rigidity is one of the most important material property due to the fact that most of the components used in engineering are submitted to loading only within the elastic regime. Material rigidity is defined as its ability to withstand deformations and it can be quantified by tensile test [16].

One of the main effects of adding mineral fillers in polymers is the increase of elastic modulus. It can be said that elastic modulus, or Young's modulus, is one of the most measured and that is why it has the largest number of models that try to predict its value.

There is still no consensus among researchers regarding the best model to be applied. Each model is more suited to some specific situation; therefore, no model responds satisfactorily to all composites.

Most of the models used in dispersed systems are derived from Einstein equations ((1) and (2)), which were development for rigid and spherical particles, at low concentrations $(1-2 \%)[17,18]$. Obviously, these hypotheses deviated the result determined by the model from the real situation.

$$
\begin{aligned}
\frac{E c}{E m}= & 1+2.5 * \mathrm{Vp} \\
\frac{E c}{E m}= & \exp \left(2.5 * \mathrm{Vp}+0.407 *(P-1)^{1.508}\right. \\
& * \frac{V p}{1-s * V p}
\end{aligned}
$$

where Ec/Em is the ration between composite and matrix Young's Modulus; Vp is the filler volume fraction; $s$ is a factor related to the adhesion and interaction effect between filler and matrix and $\mathrm{P}$ factor the aspect ratio of the filler.

In 1945, Guth [19] developed a new equation for concentrations up to $30 \%$, adding a term which compensates the interaction effect between particle filler, as shown in

$$
E c=E m *(1+2.5 * \mathrm{Vp})+14.1 * V p^{2}
$$

For fillers with variable shape (anisotropic particles), another factor (a shape factor, $\mathrm{f}$ ) was added:

$$
E c=\operatorname{Em} *\left(1+0.67 * f * \mathrm{Vp}+1.62 * f^{2} * V p^{2}\right)
$$

In 1956, Kerner developed one of the most used models to describe the elastic behavior of polymeric materials, loaded with rigid particles. This model considers dispersed spheres in a matrix where the adhesion is perfect between particle and matrix. It is assumed that the influence of a particle over the matrix properties is relevant up to a certain distance, from which the matrix has homogeneous properties. The properties in the interface region are intermediates in relation to matrix and particle properties [20]. When the mineral filler is much more rigid in relation to the matrix, the following below is used:

$$
E c=\mathrm{Em} *\left[1+\left(15 * \mathrm{Vp} * \frac{(1-\nu \mathrm{m})}{(1-\nu \mathrm{m})(8-10 \nu \mathrm{m})}\right]\right.
$$

where $\nu \mathrm{m}$ is the Poisson's coefficient of the matrix, which is for PP equal to 0.447 [20]. In 1970, Nielsen modified the Kerner expression and proposed a model called Kerner-Nielsen (kn) [18].

$$
E c=\mathrm{Em} *\left[1+\frac{(\mathrm{Akn} * \mathrm{Bkn} * \mathrm{Vp})}{(1-\mathrm{Bkn} * \mathrm{Vp})}\right]
$$

where

$$
\begin{aligned}
& A k n=\frac{(7-5 * \nu \mathrm{m})}{(8-10 * \nu \mathrm{m})} \\
& B k n=\frac{(\mathrm{Ef} / \mathrm{Em}-1)}{(\mathrm{Ef} / \mathrm{Em}+\mathrm{Akn})}
\end{aligned}
$$

where Ef is the filler's elastic modulus.

Tsai and Halpin suggested a model for randomly distributed short fiber, which can also be applied for anisotropic fillers as talc [21]. This model, the following, takes filler geometry in predicting the elastic modulus of the composites:

$$
\begin{aligned}
\frac{E c}{E m} & =\left[1+\frac{\mathrm{A} * \mathrm{~B} * \mathrm{Vp}}{(1-\mathrm{B} * \mathrm{Vp})}\right] \\
A & =2 * \frac{\mathrm{L}}{\mathrm{D}} \\
B & =\frac{(\mathrm{Ef} / \mathrm{Em}-1)}{(\mathrm{Ef} / \mathrm{Em}+\mathrm{A})}
\end{aligned}
$$

where $\mathrm{L} / \mathrm{D}$ is the aspect ratio of the filler, which is the ratio of length (L) to a thickness (D) of the filler particles.

Although there are several studies using mathematical models to evaluate and predict the mechanical behaviour of composites $[6,8,22-28]$, this work also relates to the filler characteristics and processing conditions with the mechanical behavior observed. Thus, the purpose of the present study was to assess the effect of two grades of talc (Talc A and Talc B), with different features (aspect ratio, particle size distribution, and surface area) on composite's final properties, comparing different processing conditions. Correlation 
TABLE 1: BET and MALLS results of fillers' analyse.

\begin{tabular}{llccccr}
\hline \multirow{2}{*}{ Filler } & \multicolumn{2}{c}{ Specific surface area $\left[\mathrm{m}^{2} / \mathrm{g}\right]$} & \multicolumn{2}{c}{ Pore Volume $[\mathrm{cm} / \mathrm{g}]$} & \multicolumn{2}{c}{ D50 $[\mu \mathrm{m}]$} \\
& BET & MALLS & BET & MALLS & BET & - \\
\hline TalcA & 5.35 & 2.08 & 0.02 & - & - & -1.32 \\
TalcB & 4.79 & 0.73 & 0.02 & - & - \\
\hline
\end{tabular}

between mechanical behavior and dispersion/distribution filler in iPP matrix was also evaluated. Beyond this, different mathematical models were also applied in order to predict the mechanical behavior of the composites.

\section{Materials and Methods}

3.1. Materials. Polyprolene (H605) was supplied by Braskem, with melt flow index (MFI) of 2.1 g.10min-1 and specific gravity of $0.905 \mathrm{~g} . \mathrm{cm}^{-3}$. Talc Jetfine $1 \mathrm{H}$ (Talc A) and Talc Talcmag GM-30 (Talc B) were supplied by Imerys and Magnesita, respectively. According to the suppliers, the talc grades were not coated with any coupling agent.

3.2. Filler Characterization. The surface area and pore volume were determined by BET method, using a surface area analyzer ASAP. The particle size distribution and $\mathrm{D}(50)$ values were determined by MALLS (Multi-Angle Laser Light Scattering), in a Hydro 2000 MU, MALVERN Instruments, using water and ultrasound as dispersant. The aspect ratio of the fillers (Talc A and Talc B) was determined by using a scanning electron microscopy (Jeol Microscopy, model JSM$6490 \mathrm{LV}$, accelerating voltage of $30 \mathrm{kV}, 3,000 \mathrm{X})$.

3.3. Composite and Sample Preparation. Neat iPP and iPP/ Talc composites were prepared in a twin-screw extruder (TeckTrill, model DCT-20) with screw diameter of $20 \mathrm{~mm}$, $\mathrm{L} / \mathrm{D}=36$, and screw speed of $400 \mathrm{rpm}$. The temperature profile was set at $90-210^{\circ} \mathrm{C}$. The screw profile consisted in five KB45 kneading elements at compression zone, assuring the complete fusion of the polymer and leading to good filler dispersion in the polymer matrix.

Composites of iPP and talc were prepared with the following iPP/talc compositions: 95/5, 92.5/7.5, 90/10, and 88.5/12.5 by weight. All these compositions were prepared from a masterbatch dilution step and the composites were called as MTalcA and MTalcB. The masterbatches were previously obtained by extrusion of iPP/talc (6:4) composition at 80 $\mathrm{rpm}$ and temperature profile set at $150-210^{\circ} \mathrm{C}$. Only the $90 / 10$ compositions, with the different talc grades, were prepared with and without the masterbatch dilution step in order to compare both procedures. Neat iPP was also processed in the same conditions of the composites.

The samples were subjected to injection process (Arburg, Allrounder $270 \mathrm{~S}$ model), at temperature profile set at 210 $250^{\circ} \mathrm{C}$ from rear to injection nozzle, mold temperature at $50^{\circ} \mathrm{C}$ and back pressure at $300 \mathrm{bar}$, to produce the specimens (Type I) for tensile test, according to ASTM D638.

3.4. Composite Characterization. Tensile tests were carried out at 50mm.min-1, according to ASTM D638 with specimens of Type 1. The morphology of the iPP/Talc composites was investigated by studying cryogenic fractured surfaces using a scanning electron microscope (SEM, Jeol Microscopy, model JSM-6490LV, accelerating voltage of $30 \mathrm{kV}, 7,500 \mathrm{X})$. The fractured samples were coated with gold particles before the experiment.

\section{Results and Discussion}

4.1. Filler Characterization. Table 1 shows the BET and MALLS results. As already known, the smaller the particle size the greater its specific surface area (SSA) and the greater the pore volume and the pore number, higher the SSA value.

Figure 1 shows the particle size distribution curves for Talc A and Talc B, respectively. The SEM micrographs of Talc fillers are also showed. Table 1 also presents the data determined from Figure 1.

Based on Table 1 and on BET results, as the talc fillers have similar values of SSA and pore volume, it could be assumed that both fillers tend to provide similar influences when added to iPP matrix. However, other filler characteristics should also be considered.

Figure 1 shows that Talc A, even though presents a smaller particle size in relation to Talc $B$, its size distribution is larger. The size distribution of Talc B is similar to a monomodal distribution and, beyond this, Talc B particles appear to tend to agglomerate less in relation to Talc A particles, as showed in SEM micrographs. Table 1 (MALLS results) also shows that Talc B has a smaller specific surface area (larger particle size) than Talc A, as can also be observed in SEM micrographs. The difference between the BET and MALLS results is because BET analysis is related to the total specific surface area of the particle and the superficial area of all porous structures, while MALLS analysis only gives the specific surface area of the particle.

The literature reveals that smaller particle size leads to the increase of interfacial tension. Another important factor to be considered is the filler behavior during the processing step; filler with different distribution from monomodal tends to agglomerate during processing.

The filler's aspect ratios were determined from SEM micrographs and the results are the following: 3 for Talc A and 7 for Talc B. According to De Armitt [7], fillers with aspect ratio range of 5 to 50 are platy-type and are used when the increase of composite elastic modulus is desired. This behavior is because, in this range, the aspect ratio is high enough to promote the increase composites' rigidity and still be small enough to keep its anisotropic effect.

4.2. Young's Modulus of $i P P$ and $i P P / T a l c$ Composites. Figure 2 shows the results of tensile tests of neat iPP and iPP/Talc 

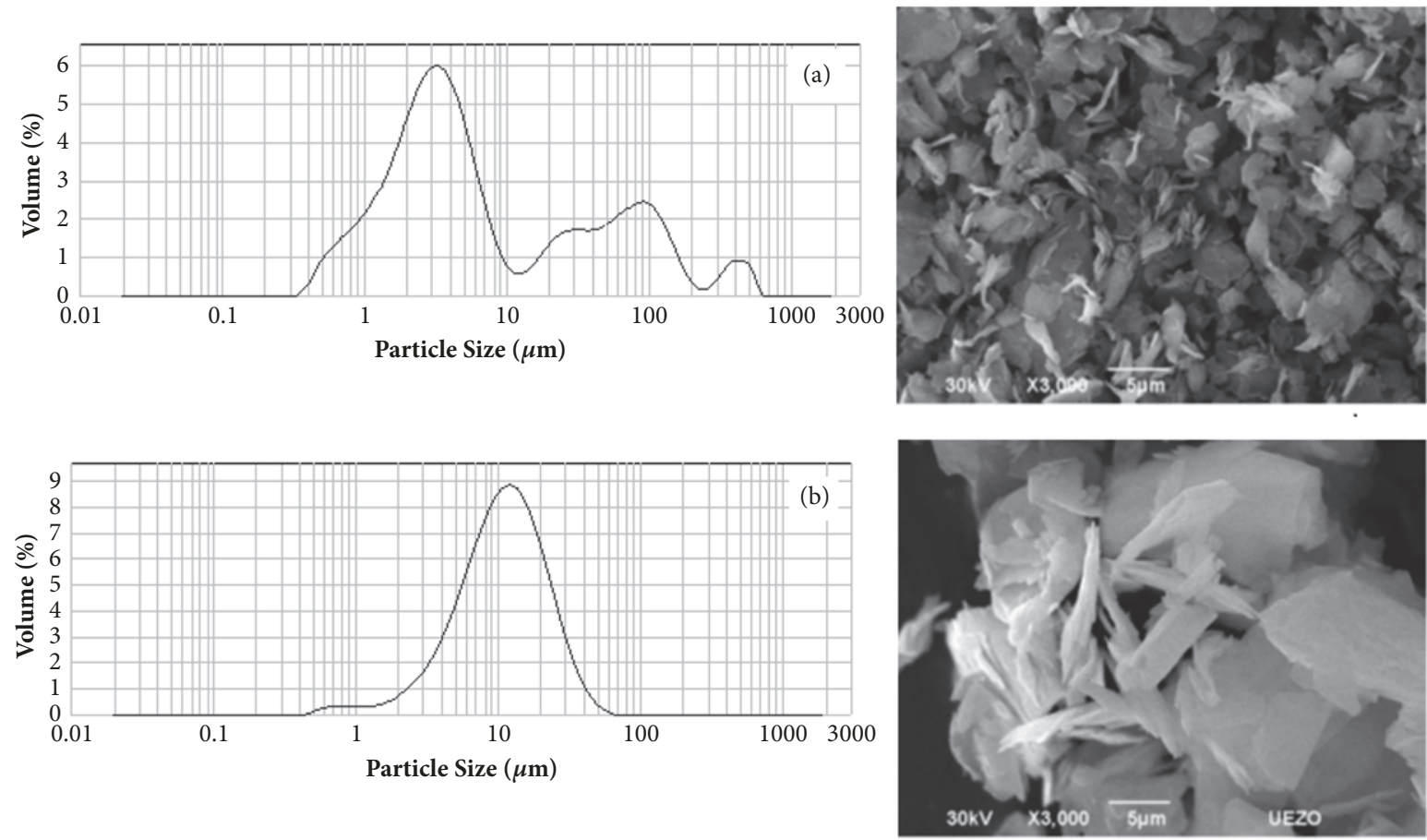

Figure 1: Particle size distribution and SEM micrographs of (a) Talc A and (b) Talc B.

(Talc A and Talc B) composites prepared with all components being fed simultaneously and from masterbath dilution. The figure also shows the SEM micrographs of the iPP/Talc A and iPP/Talc B composites. This evaluation was realized in the iPP/Talc (90/10, wt.\%) composition.

Figure 2 shows that the addition of talc fillers increased Young's modulus value of iPP, indicating its reinforcing effect on the matrix. iPP/Talc A composite produced from masterbatch dilution step presents high Young's modulus value, similar to the iPP/Talc B composite produced without masterbatch step. Although Talc B filler presents higher particle size, this filler also presents a narrower size distribution and an aspect ratio value more adequate to increase the elastic modulus of the final composite, as mentioned before. These characteristics predominated over the particle size parameter, leading to a good dispersion of the filler in iPP matrix. This behavior was observed without masterbatch step.

Differently from Talc B, Talc A filler, despite having a smaller particle size (higher specific superficial area), its wide size distribution did not favor the particle dispersion in such an efficient way, as well as its low aspect ratio value in relation to Talc B. According to Ségard et al. [29], particles with a high aspect ratio contribute more significantly to increase the rigidity of the material due to the better transmission of the interfacial shear stresses exhibits by the matrix to the filler. Only when the processing was conducted by using a masterbatch dilution step, a good dispersion of the Talc A filler was achieved, leading to high Young's modulus value. Comparing iPP/MTalcA and iPP/TalcA composites, SEM micrographs show that iPP/MTalcA composite presents a platy structure of the filler, which contributes to the increase of the rigidity property of the composite. In other words, the masterbatch step promoted a more efficient dispersion of the Talc A in the iPP matrix, by segregating the filler particles as platy structures and achieving an alignment of the talc lamellaes during processing.

An interesting result was found to iPP/Talc B composite produced from masterbatch step. This procedure seems not to have led to an efficient dispersion and part of aggregates formed during concentrate production (masterbatch production) could not segregate in the subsequent dilution step, under the processing conditions performed. These results show that not only filler characteristics but also the processing methodology performance influence the dispersion of the filler in the polymer matrix and, consequently, on the final properties of the composite. Talc B filler presents a monomodal distribution, which contributes to the filler dispersion; however, its larger particle size can promote the particle agglomeration if the processing conditions were not enough to achieve an efficient dispersion. These results were also evidenced in the literature. Echevarría et al. [30] studied the influence of processing parameters on mechanical properties of injection molded $\mathrm{PP} /$ talc composites. The authors showed that melting and mold temperatures, as well as injection speed and screw rotation rate, influence the mechanical properties. Researches [31, 32] showed that filler characteristics, such as particle size, as well as shear conditions, influenced its dispersion on the PP matrix crystallization kinetics and, consequently, the final composite properties. The SEM micrographs corroborate the mechanical results.

Figure 3 shows Young's modulus property of the iPP/Talc $\mathrm{A}$ and $\mathrm{iPP} / \mathrm{Talc} \mathrm{B}$ composites with different talc content. The composites were produced by using masterbatch dilution step. 

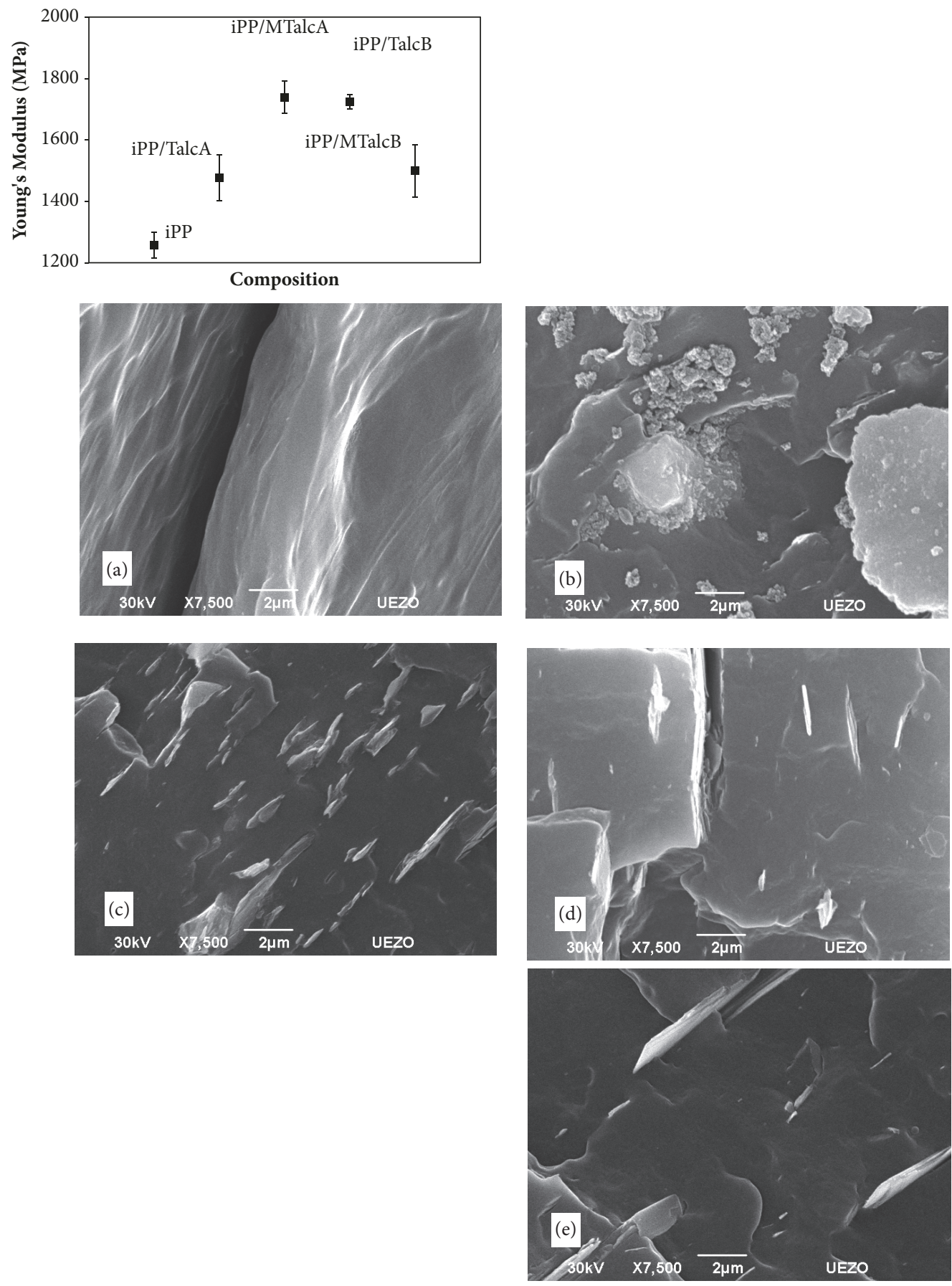

FIGURE 2: Young's modulus versus composition iPP/Talc (90/10, wt.\%) in different processing procedure: all components being fed simultaneously (iPP/Talc A and iPP/Talc B composites) and from masterbath dilution (iPP/MTalc A and iPP/MTalc B composites). SEM micrographs (a) neat iPP; (b) iPP/Talc A; (c) iPP/MTalc A; (d) iPP/Talc B; and (e) iPP/MTalc B.

Figure 3 shows that, up to 5 wt.\%, iPP/MTalc A and iPP/MTalc B composites present similar Young's modulus values, indicating that, up to 5 wt.\% of talc in iPP matrix, the filler characteristics did not affect significantly the stiffness of the composites. This result indicates that only the shear conditions seem to be responsible for the dispersion mechanism of the filler particles in the iPP matrix. Only at higher talc content, differences in rigidity property can be observed between the composites. The addition of $7.5 \mathrm{wt} . \%$ of Talc B tends to produce a composite with higher Young's modulus value in relation to $\mathrm{iPP} / \mathrm{Talc} \mathrm{A}$ composite, which tends to keep its property constant up to $10 \mathrm{wt} . \%$ of filler. When $10 \mathrm{wt} . \%$ of Talc B was added, a different behavior was observed: a significant decrease in Young's modulus value occurred and then, at the addition of $12.5 \mathrm{wt} . \%$ of Talc B, an increase in stiffness property of the composite was again 

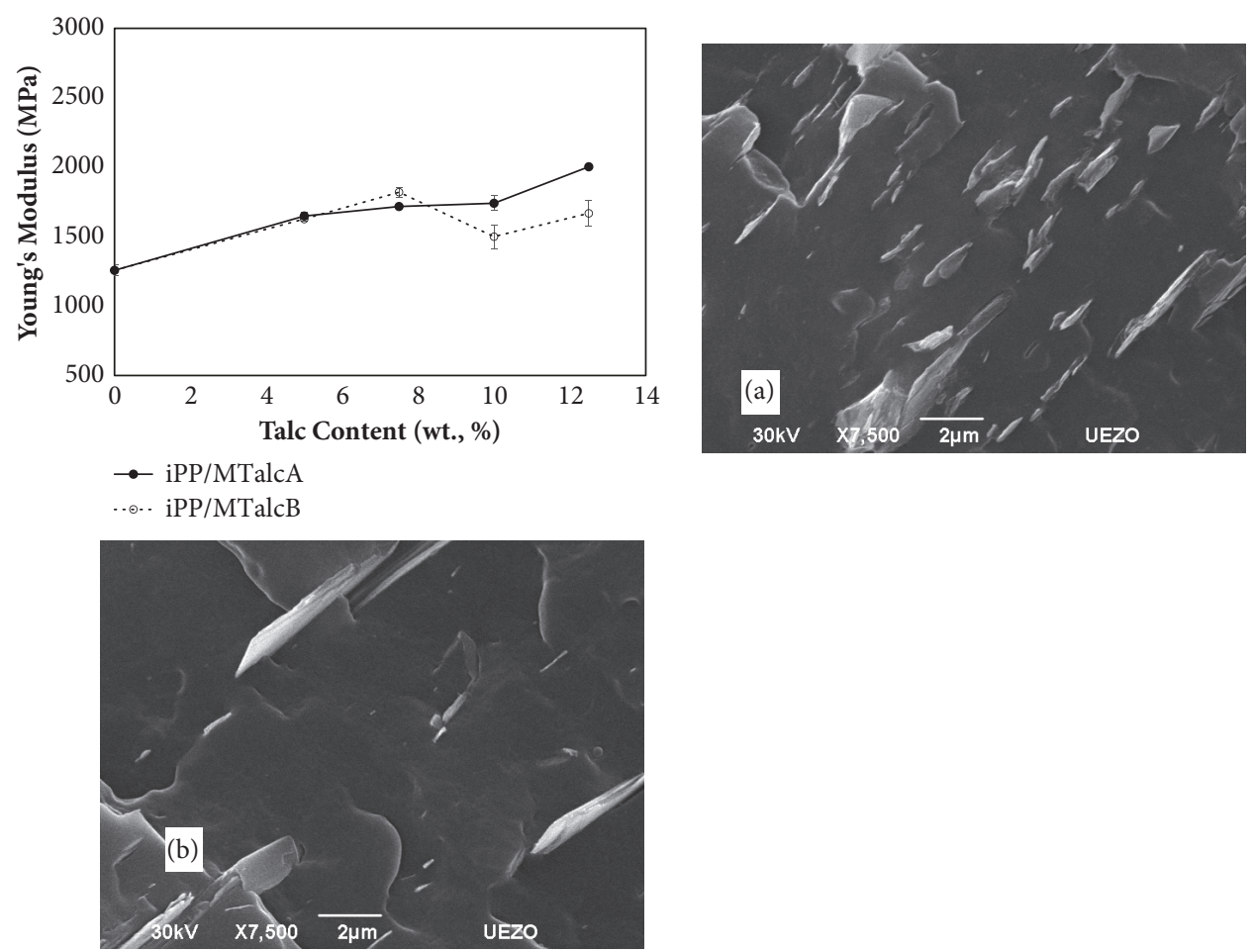

FIGURE 3: Young's modulus $x$ filler content curves of composites based on iPP/Talc, obtained by masterbatch dilution step. SEM micrographs: (a) iPP/MTalc A and (b) iPP/MTalc B.

observed, although it is still smaller in relation to iPP/MTalc A composite. This behavior indicates that, to higher filler contents, particle size effect predominated over dispersion mechanism. In other words, as particle volume fraction of Talc B increased and, due to its larger particle size, the mean number of the neighboring particles increased and, consequently, also the probability to particle agglomeration. Talc A, for presenting smaller particle size (higher specific superficial area) in relation to Talc B, presents a greater interaction with iPP matrix and, thus, a better dispersion is achieved even in condition with high filler content. SEM micrographs show the better talc dispersion achieved for iPP/MTalcA composite and the alignment direction of Talc A particles.

4.3. Mathematical Modeling. Different theoretical models were applied to predict the reinforcing effect of the talc grades on Young's modulus of the iPP composites.

Figures 4 and 5 shows Young's Modulus of iPP/talc composites, Ec, calculated experimentally and predicted by Kerner-Nielsen and Halpin-Tsai Models, respectively.

Figure 4 shows that the experimental curves of both composites (iPP/MTalcA and iPP/MTalcB) are above values predicted by Kerner-Nielsen's Model. It is because talc fillers have an aspect ratio greater than 1 , which favors the anchoring of the filler in the iPP matrix, increasing Young's modulus values. Beyond this, as shown in SEM micrographs, the alignments of the platy structure of the fillers are also responsible for the increase of Young's modulus values of the composites. It is important to emphasize that Kerner-Nielsen's Model does

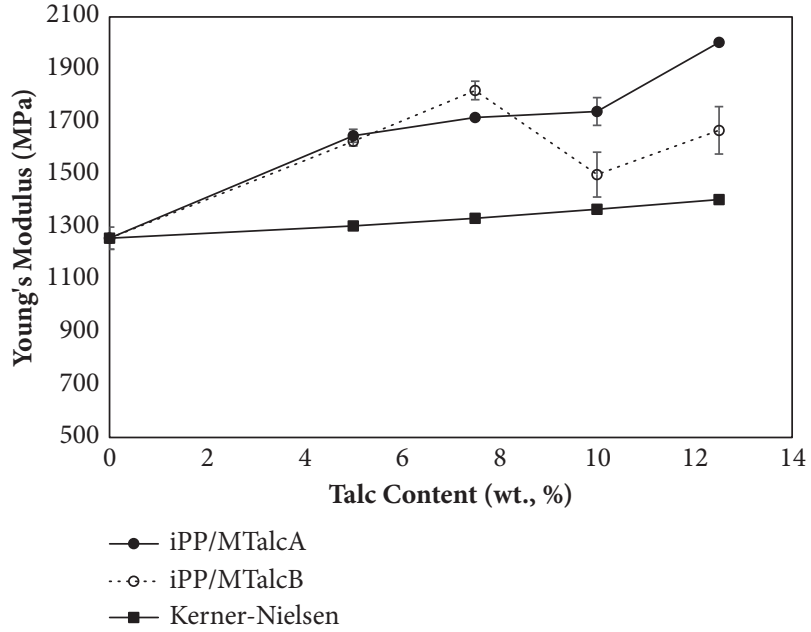

FIGURE 4: Young's modulus versus filler content curves of composites based on iPP/MTalc A and iPP/MTalc B, experimental data and predicted values determined by Kerner-Nielsen Model.

not consider the effect of the filler geometry in predicting the modulus of the composites.

Figure 5 shows that the experimental values for iPP/ MTalcA and iPP/MTalcB composites are closer to values predicted by Halpin-Tsai Model in relation to Kerner-Nielsen, indicating that Halpin-Tsai Model is more adequate in the prediction of rigidity property of the composites studied. It could happen because Halpin-Tsai equation considers the 


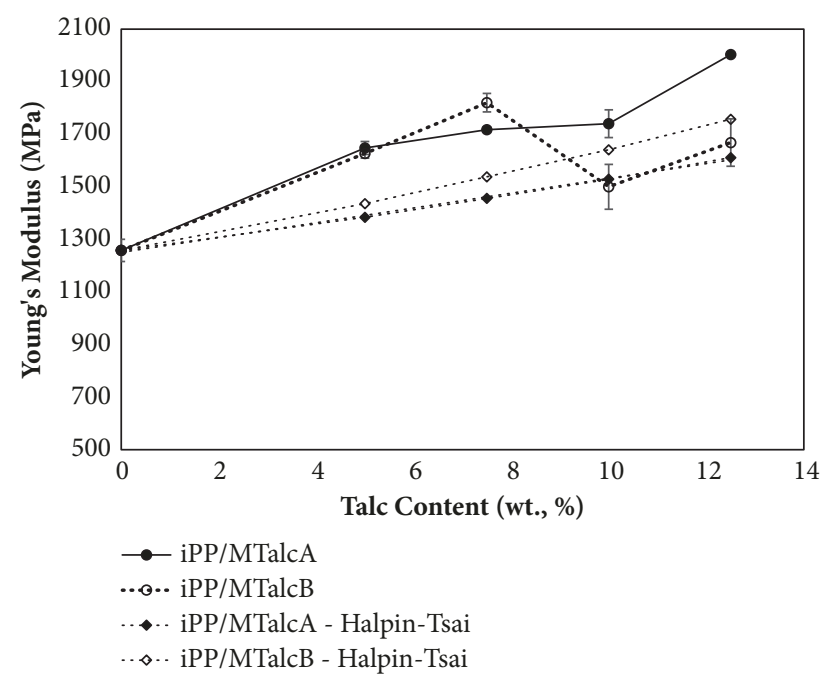

FIGURE 5: Young's modulus versus filler content curves of composites based on iPP/MTalc A and iPP/MTalc B, experimental data and predicted values determined by Halpin-Tsai Model.

effect of filler geometry in predicting elastic modulus of the composites. However, it can also be observed that all experimental values of iPP/MTalcA composite are above values predicted by Halpin-Tsai Model, showing again the pronounced effect of the Talc A filler as reinforcing agent in all compositions analyzed. Another behavior is observed for iPP/MTalcB composites: up to $7.5 \mathrm{wt} . \%$ of filler, the experimental values are above values predicted by the model, indicating the efficient action of Talc B filler as reinforcing agent in iPP matrix at low contents and processed by masterbatch dilution. However, at higher contents, from 7.5 wt.\%, the addition of the filler leads to the decrease of the rigidity of the final composite and at around $9.5 \mathrm{wt} . \%$, and values of Young's modulus below the values predicted by the model are obtained, signalizing a significant decrease in the reinforcing effect of the Talc B in the processing conditions used. This behavior is evidence that not only the filler's characteristics but also the mixing procedure adopted must be taken into account in the prediction of the mechanical performance of the composites. As increasing particle volume fraction of Talc B and due to its higher particle size, the mean number of the neighboring particles increases and, consequently, also the probability to form particle agglomeration. This is a reason to observe the decrease of Young's modulus values in the iPP/MTalcB composites with higher filler content.

The model from Guth equation, developed for composites with anisotropic particles, Modified Guth Model (4), was also applied. Figure 6 shows Young's Modulus of iPP/talc composites, Ec, calculated experimentally and predicted by the model.

As Halpin-Tsai Model, Modified Guth Model also considers the effect of filler geometry in predicting elastic modulus of the composites. It seems that, for iPP/MTalcB composite at higher TalcB filler content (from $10 \mathrm{wt} . \%$ up to $12.5 \mathrm{wt} . \%$ of Talc B), the experimental data were well predicted by the model.

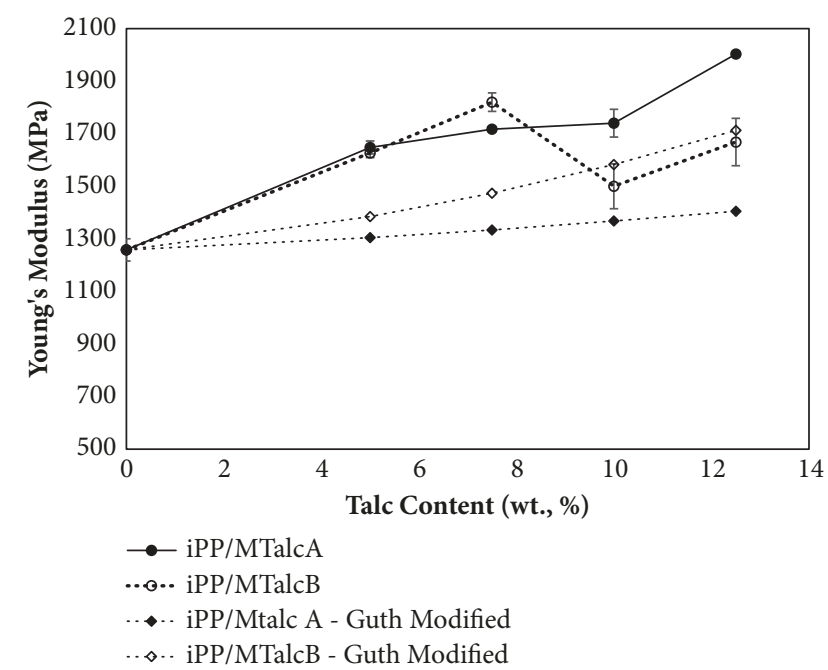

FIGURE 6: Young's modulus versus filler content curves of composites based on iPP/MTalc A and iPP/MTalc B, experimental data and predicted values determined by Modified Guth Model.

\section{Conclusions}

It is known that the final mechanical properties of talc filled thermoplastic composites are dependent on the inherent characteristics of the filler and the dispersion of the particles in the polymer matrix. The present study showed that even with different characteristics, Talc A and Talc B may present similar and different mechanical behavior, depending on the filler content added and the processing methodology used. In general, masterbatch dilution procedure showed an improvement on filler's dispersion in iPP matrix. However, for composites where filler presents a low surface contact, the masterbatch dilution step was not enough to improve the interaction between iPP and filler and a better dispersion was achieved when filler and resin were blended without masterbatch procedure.

The micromechanics models for particulate composites showed that not only must the filler's characteristics be taken into account in the prediction of the mechanical performance of the composites, but also the mixing procedure plays an important role in the final properties.

\section{Data Availability}

The data used to support the findings of this study are available from the corresponding author upon request.

\section{Conflicts of Interest}

The authors declare that there are no conflicts of interest regarding the publication of this paper.

\section{Acknowledgments}

The authors are grateful for Imerys and Magnesita and BRASKEM companies for providing the talcs and iPP resin, respectively, and CAPES for the scholarship grants. 


\section{References}

[1] E. Kluenker, J. Faymonville, K. Peter, M. Moeller, and C. Hopmann, "Reactive extrusion processing of polypropylene/SiO2 nanocomposites by in situ synthesis of the nanofillers: Experiments and properties," Polymer (United Kingdom), vol. 55, no. 21, pp. 5370-5380, 2014.

[2] F. Qiu, Y. Hao, X. Li, B. Wang, and M. Wang, "Functionalized graphene sheets filled isotactic polypropylene nanocomposites," Composites Part B: Engineering, vol. 71, pp. 175-183, 2015.

[3] E. M. Do Nascimento, D. Eiras, and L. A. Pessan, "Effect of thermal treatment on impact resistance and mechanical properties of polypropylene/calcium carbonate nanocomposites," Composites Part B: Engineering, vol. 91, pp. 228-234, 2016.

[4] J.-Z. Liang, "Reinforcement and quantitative description of inorganic particulate-filled polymer composites," Composites Part B: Engineering, vol. 51, pp. 224-232, 2013.

[5] E. Pérez, V. Alvarez, C. J. Pérez, and C. Bernal, "A comparative study of the effect of different rigid fillers on the fracture and failure behavior of polypropylene based composites," Composites Part B: Engineering, vol. 52, pp. 72-83, 2013.

[6] Y. Zare, "Modeling the yield strength of polymer nanocomposites based upon nanoparticle agglomeration and polymer-filler interphase," Journal of Colloid and Interface Science, vol. 467, pp. 165-169, 2016.

[7] C. DeArmitt and R. Rothon, "Dispersants and Coupling Agents," Applied Plastics Engineering Handbook, pp. 441-454, 2011.

[8] T. Nassaji and Y. Zare, "Modeling the strength and thickness of the interphase in polymer nanocomposite reinforced with spherical nanoparticles by a coupling methodology," Journal of Colloid and Interface Science, vol. 465, pp. 342-346, 2016.

[9] J. Móczó and B. Pukánszky, "Polymer micro and nanocomposites: structure, interactions, properties," Journal of Industrial and Engineering Chemistry, vol. 14, no. 5, pp. 535-563, 2008.

[10] M. M. Rueda, M. Auscher, and R. Fulchiron, "Rheology and applications of highly filled polymers: a review of current understanding," Progress in Polymer Science, vol. 66, pp. 22-53, 2017.

[11] H. U. Zaman and M. D. H. Beg, "Effect of CaCO3 contents on the properties of polyethylene nanocomposites sheets," Fibers and Polymers, vol. 15, no. 4, pp. 839-846, 2014.

[12] B. Duleba, E. Spišák, and F. Greškovič, "Mechanical properties of PA6/MMT polymer nanocomposites and prediction based on content of nanofiller," in Proceedings of the Modelling of Mechanical and Mechatronic Systems, MMaMS 2014, pp. 75-80.

[13] F. Qiu, M. Wang, Y. Hao, and S. Guo, "The effect of talc orientation and transcrystallization on mechanical properties and thermal stability of the polypropylene/talc composites," Composites Part A: Applied Science and Manufacturing, vol. 58, pp. 7-15, 2014.

[14] K. Wang, N. Bahlouli, F. Addiego et al., "Effect of talc content on the degradation of re-extruded polypropylene/talc composites," Polymer Degradation and Stability, vol. 98, no. 7, pp. 1275-1286, 2013.

[15] B. Fiorentino, R. Fulchiron, V. Bounor-Legaré, J.-C. Majesté, J. C. Leblond, and J. Duchet-Rumeau, "Chemical modification routes of synthetic talc: Influence on its nucleating power and on its dispersion state," Applied Clay Science, vol. 109-110, pp. 107-118, 2015.

[16] S. Díez-Gutiérrez, M. A. Rodríguez-Pérez, J. A. De Saja, and J. I. Velasco, "Dynamic mechanical analysis of injection-moulded discs of polypropylene and untreated and silane-treated talcfilled polypropylene composites," Polymer Journal, vol. 40, no. 19, pp. 5345-5353, 1999.

[17] A. Einstein, Investigation on the Theory of the Brownian Movement, Dover Publications, New York, NY, USA, 1956.

[18] B. Pukánszky, K. Belina, A. Rockenbauer, and F. H. J. Maurer, "Effect of nucleation, filler anisotropy and orientation on the properties of PP composites," Composites Part B: Engineering, vol. 25, no. 3, pp. 205-214, 1994.

[19] E. Guth, "Theory of filler reinforcement," Journal of Applied Physics, vol. 16, no. 1, pp. 20-25, 1945.

[20] L. E. Nielsen, "Dynamic Mechanical Properties of Filled Polymers," in Proceedings of the Applied Polymer Symposium, vol. 12, pp. 249-265, 1969.

[21] A. Shakoor and N. L. Thomas, "Talc as a nucleating agent and reinforcing filler in poly(lactic acid) composites," Polymer Engineering \& Science, vol. 54, no. 1, pp. 64-70, 2014.

[22] E. Freire, E. E. C. Monteiro, and J. C. R. Cyrino, Propriedades Mecânicas de Compósitos de Polipropileno com Fibra de Vidro, Polímeros: Ciência e Tecnologia, 1994.

[23] S.-Y. Fu, X.-Q. Feng, B. Lauke, and Y.-W. Mai, "Effects of particle size, particle/matrix interface adhesion and particle loading on mechanical properties of particulate-polymer composites," Composites Part B: Engineering, vol. 39, no. 6, pp. 933-961, 2008.

[24] C.-M. Chan, J. S. Wu, J.-X. Li, and Y.-K. Cheung, "Polypropylene/calcium carbonate nanocomposites," Polymer Journal, vol. 43, no. 10, pp. 2981-2992, 2002.

[25] J. C. Halpin, "Stiffness and Expansion Estimates for Oriented Short Fiber Composites," Journal of Composite Materials, vol. 3, no. 4, pp. 732-734, 1969.

[26] Y. Zare, "Development of Halpin-Tsai model for polymer nanocomposites assuming interphase properties and nanofiller size," Polymer Testing, vol. 51, pp. 69-73, 2016.

[27] R. K. Goyal, A. N. Tiwari, and Y. S. Negi, "Microhardness of PEEK/ceramic micro- and nanocomposites: Correlation with Halpin-Tsai model," Materials Science and Engineering: A Structural Materials: Properties, Microstructure and Processing, vol. 491, no. 1-2, pp. 230-236, 2008.

[28] M. J. Clifford and T. Wan, "Fibre reinforced nanocomposites: Mechanical properties of PA6/clay and glass fibre/PA6/clay nanocomposites," Polymer Journal, vol. 51, no. 2, pp. 535-539, 2010.

[29] E. Ségard, S. Benmedakhene, A. Laksimi, and D. Laï, "Influence of the fibre-matrix interface on the behaviour of polypropylene reinforced by short glass fibres above glass transition temperature," Composites Science and Technology, vol. 62, no. 15, pp. 2029-2036, 2002.

[30] G. Guerrica-Echevarría, J. I. Eguiazábal, and J. Nazábal, “Influence of molding conditions and talc content on the properties of polypropylene composites," European Polymer Journal, vol. 34, no. 8, pp. 1213-1219, 1998.

[31] B. Fiorentino, R. Fulchiron, J. Duchet-Rumeau, V. BounorLegaré, and J.-C. Majesté, "Controlled shear-induced molecular orientation and crystallization in polypropylene/talc microcomposites - Effects of the talc nature," Polymer (United Kingdom), vol. 54, no. 11, pp. 2764-2775, 2013.

[32] A. Ariffin, S. S. Jikan, M. S. F. Samsudin, Z. M. Ariff, and Z. A. M. Ishak, "Melt elasticity phenomenon of multicomponent (talc and calcium carbonate) filled polypropylene," Journal of Reinforced Plastics and Composites, vol. 25, no. 9, pp. 913-923, 2006. 

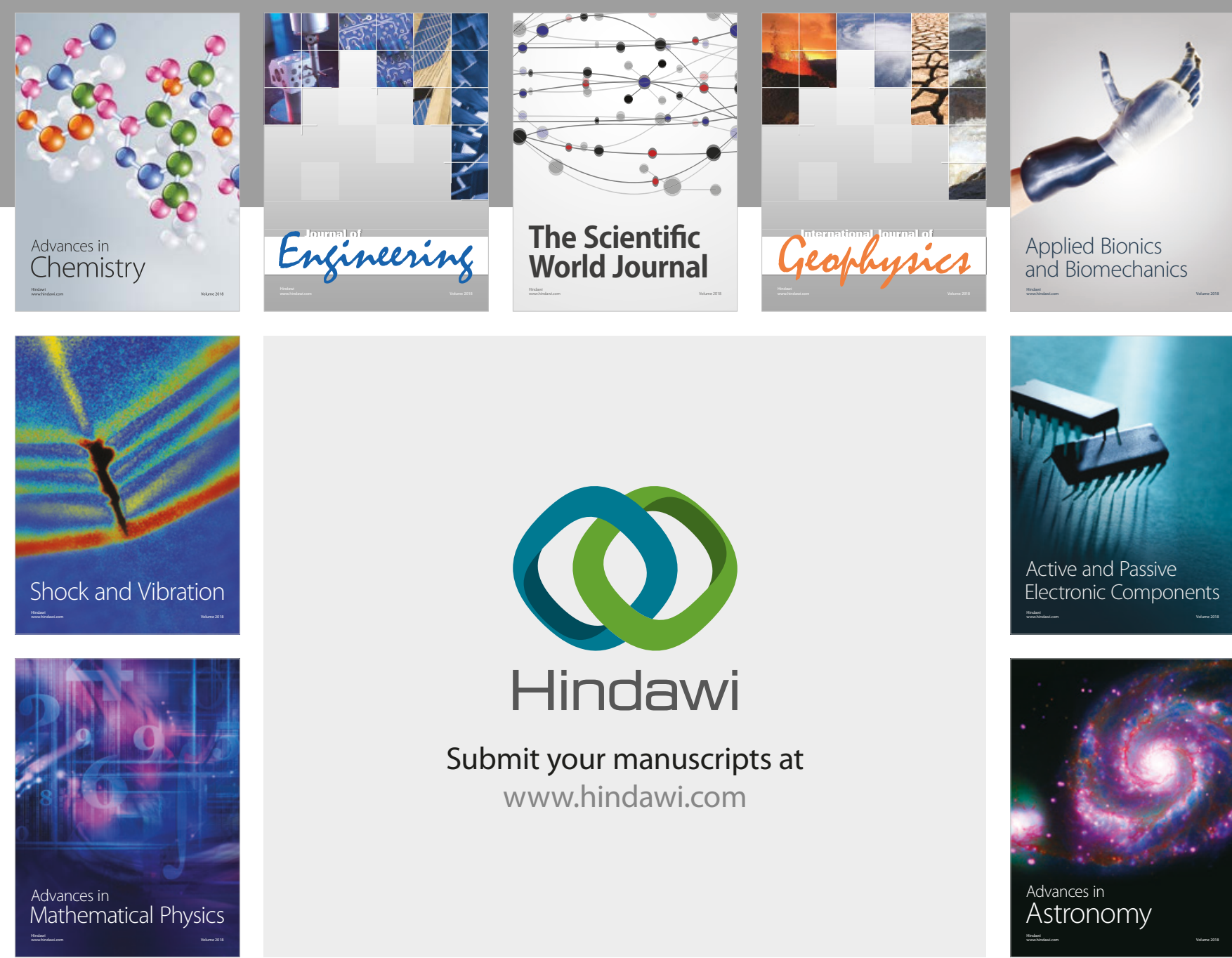

Submit your manuscripts at

www.hindawi.com

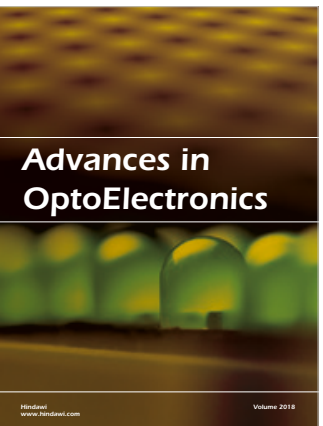

\section{Rotcting Machinery}
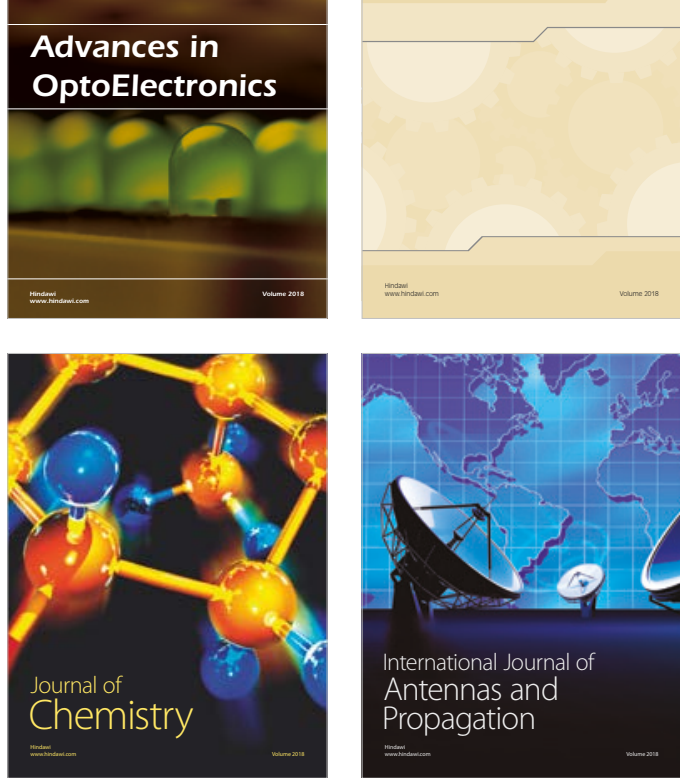

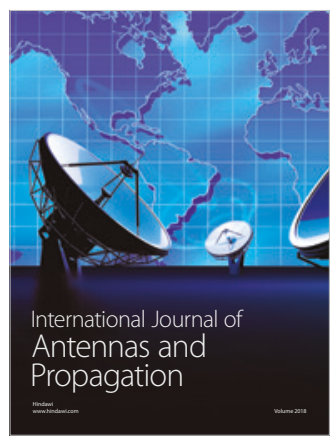

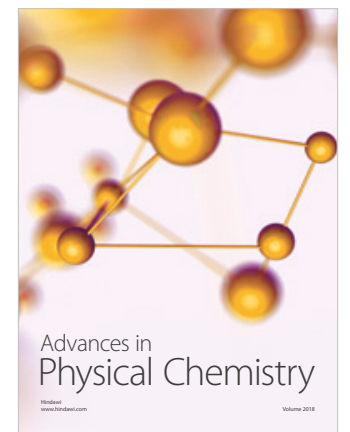

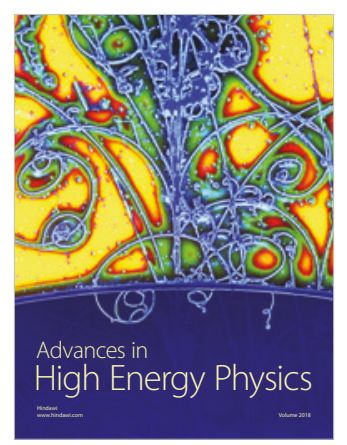

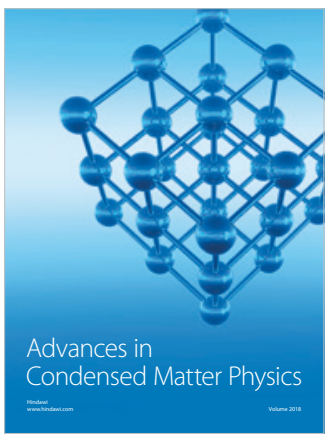

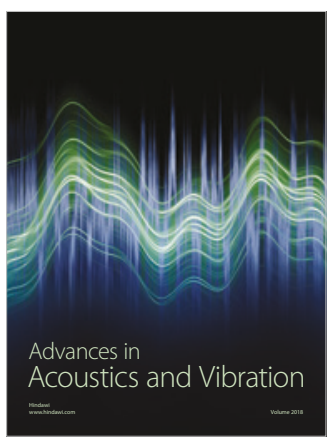

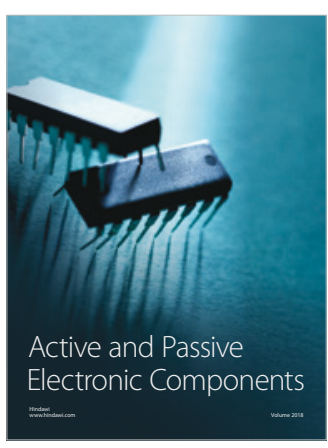
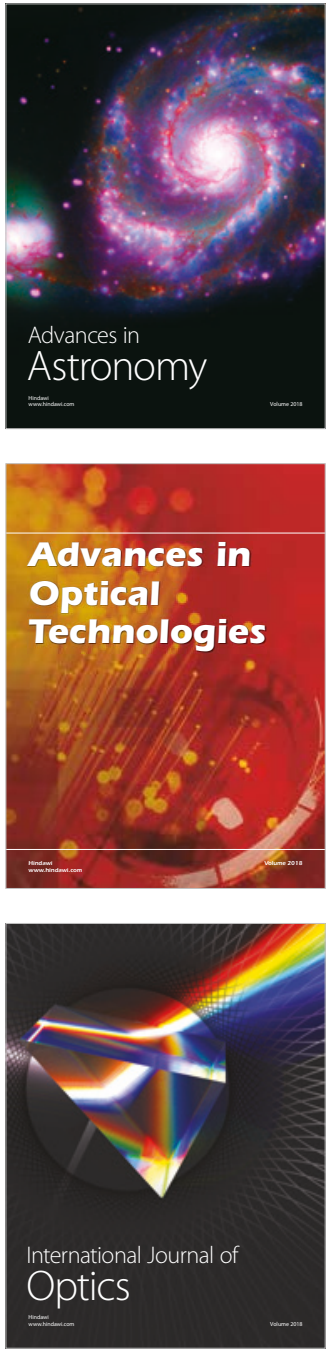